\title{
Surfaces
}

Goldscheider, Frances K. and Linda J. Waite, New Families, No Families? The Transformation of the American Home (Berkeley, Los Angeles, Oxford: University of California Press, 1991)

\section{Roxanne Rimstead}

Volume 4, 1994

URI : https://id.erudit.org/iderudit/1064982ar

DOI : https://doi.org/10.7202/1064982ar

Aller au sommaire du numéro

Éditeur(s)

Les Presses de l’Université de Montréal

ISSN

1188-2492 (imprimé)

1200-5320 (numérique)

Découvrir la revue

Citer ce compte rendu

Rimstead, R. (1994). Compte rendu de [Goldscheider, Frances K. and Linda J. Waite, New Families, No Families? The Transformation of the American Home (Berkeley, Los Angeles, Oxford: University of California Press, 1991)]. Surfaces, 4. https://doi.org/10.7202/1064982ar d'utilisation que vous pouvez consulter en ligne. 
BOOK REVIEW

F.K GOLDSCHEIDER AND L.J. WAITE, NEW FAMILIES. NO FAMILIES? THE TRANSFORMATION OF THE AMERICAN HOME

\author{
$\underline{\text { Roxanne Rimstead }}$
}

Goldscheider, Frances K. and Linda J. Waite, New Families, No Families? The Transformation of the American Home (Berkeley, Los Angeles, Oxford: University of California Press, 1991).

One might expect a recent academic study on the transformation of the family to reveal new insights into the "family-values" debate in American culture. However, Goldscheider and Waite study the family through a glass, darkly, in New Families, No Families? They imagine the future of the nation in terms of two trends alone: on the one hand, the move toward "new families, " which means, here, a more egalitarian division of sex roles than the traditional patriarchal family, and, on the other, the trend towards "no families" which seems to mean anything from the single life to childless, cohabiting heterosexual couples. We eventually find, through omissions rather than any clear definition, that "new families" are, in the context of this study, nuclear, heterosexual, reproductive families sanctioned by marriage and that non-family living is chiefly either non-procreative or nonheterosexual. Falling through this paradigm of family transformation are "old families," the reactionary return to strongly designated sex roles via family values, and any new alternative styles of family living which are not reproductive or heterosexual or nuclear. The usefulness of the central dichotomy shaping this inquiry needs to be questioned. Does the no families/ new families paradigm focus attention on major trends as it claims or does it restrict the view to dichotomous extremes? Do the alternative families which fall through the jaws of the dichotomy constitute a meaningful absence in the work -- for example, mother-led families, gay and lesbian couples, cohabiting childless couples, group co-operative arrangements, extended families, homosexual parents, shared custody parents? And, finally, does the authors' tacit refusal to engage with the more complex theoretical issue of the definition of family at the very core of their study limit their field of inquiry significantly from the outset? /pp. 4-5/ 
The opaque nature of Goldscheider and Waite's study as a whole probably stems from the use of this oversimplified interpretive device for family trends, but the issue of family transformation is also clouded throughout by the fact that questions asked of data presuppose certain values that favour reproduction and nuclear family arrangements. Though appearing at first to reflect on a clear, positivist image of dominant trends in marriage, divorce, and the division of domestic tasks, the book is actually fueled by a maternal feminist agenda which is often covertly lodged in evaluative discourse rather than sustained argument. For example, in the introduction "family" is defined as an "undervalued treasure" and then in the conclusion as "a precious resource" and, moreover, "one that can be lost simply because too few are looking at it in a scientific way when it first shows real signs of strain" (xv, 192). The implication is that science will save the family, but exactly how is never made clear. Will parents and young people correct the error of their ways once they know they are headed toward "no families"? In accordance with the subtext of values underlying this study, "no family" is usually referred to obliquely as a "risk," a "danger," even "worst case scenarios" with only the exceptional "positive effect" (21). The authors finally openly denounce non-family living as an unviable system when, in the conclusion, they link the lack of a family system based on marriage, nuclear living, and reproduction to declining fertility rates. However, it remains unclear and unconvincing why single motherhood should be an unviable system for reproducing merely because it may deprive young males of realistic male role models (201-2). But, more to the point, who said that families needed to be subordinated to one ideal system? What about variety and experimentation, not to mention choice?

Theoretical arguments aside, New Families, No Families? is probably more valuable to demographers than to the general reader as it gives detailed information on scholarship in the area and on demographic trends. By seeking answers to demographic questions about family living, Goldscheider and Waite wish to redress the long standing lack of sociological research in this area, a lack they interpret as predictable given the fact that Western culture has traditionally devalued life and work in the private sphere. They also argue that many male scholars are as anxious as other men about the current move toward more egalitarian relationships in the home and thus have been avoiding scrutinizing that particular revolution. "[T]he general scholarly view," they argue, has been to assume that single life or "no-family living" is not only a more desirable choice for the present generation than altered roles within the family, but the only option available given a pessimistic view of the decline of the family (2).

In Chapters One and Two, Goldscheider and Waite discuss the so-called decline of the family, give a rudimentary account of the historical roots of that decline, and wonder whether it should be interpreted as decline or be called "restructuring" instead. For instance, they observe that the separation of home and work into private and public spheres was a relatively recent cultural phenomenon beginning with industrialization. At the point of 
greatest separation of male and female spheres in the 1950's, they claim, the "seeds of rejection of home" were planted in the form of trivialization of housework and of the emotional function of home (8). Even after women moved back into the work force and claimed more egalitarian status in the public sphere, the authors observe, the private sphere remained a site of inequity sometimes referred to as "the second shift." Goldsheider and Waite also observe, however, that only in the mid-eighties did studies become available to show how the family was remaining fundamentally women's responsibility. Although rising divorce and the choice of non-family living currently seem to threaten pro-family living, the authors suggest that in reality these choices may lead to more egalitarian practices and the restructuring of the family. After all, they argue, the traditional family with its emphasis on segregated roles and financial dependency (rather than truly companionate marriage), was actually as fundamentally anti-family as current non-family living. According to this historical perspective, the revolution within the private sphere would reach completion not with antifamily choices (non-family living), but with a new, more egalitarian family structure (24).

In Chapter Three the authors offer a detailed look at what it means to study the family through demography and scholarly data. Here is where they carry out a sustained discussion of their own methodology, its limitations and advantages, and claim that their own method surpasses others to date since it is based on a wider sampling of the American population from the Census and the Department of Labour studies (the NLS studies of five thousand subjects over fifteen years from the late sixties to the eighties). What they gain in geographical and temporal breadth, they admit, is lost in detail because they do not interview subjects face-to-face. But they accept this loss since their goal is to discuss major trends rather than nuanced, personal case studies. They also admit a lack of data on non-family living and on men's role in families. Their goal is to predict through intergenerational links (mainly among women), which trend, new families or no families, will be dominant in the future.

Chapter Four turns to a study of young adults' attitudes and plans about career, marriage, and childbearing to see how these have been formed and if they have been lived out according to early expectations. Some interesting findings here are that marriage and childbearing figure more largely in young adults' expectations than they do in their life courses, suggesting to the authors that the reasons for non-family choices have more to do with economic realities and other difficulties than with desire. Moreover, the authors discover a definite correlation between the experience of independent living (e.g. college dormitories, periods of single life) and deferred or delayed marriages. They conclude that if women's egalitarian expectations from increased experience of independent living -- which shows them they are capable of self-support and also shows them the sort of work demands involved in domestic life - -- are not met with enough available egalitarian men, the transformation of the family will tend increasingly towards non-family living. The next two chapters follow the life path of a 
majority from marriage to parenting to divorce. One finding here is that the greatest factor in divorce rates are early marriages which do not result, necessarily, from traditional family histories, suggesting that one generation will not automatically reproduce the previous generation's family patterns. The authors conclude that the strongest challenge to choosing marriage and parenting comes not from the increased options of non-family living but from the threat of inequity in the traditional family. For example, studies now show that women whose husbands do not help with domestic chores are more likely to consider divorce than those whose husbands have more egalitarian attitudes.

I found Chapters Seven, Eight, and Nine the most interesting in that they dissect the emotive issue of housework and lay out trends and inequities with skeletal clarity. For example, in Chapter Seven, "Family Structure and Husbands' Share in Household Tasks," the types of tasks done at home are charted along with how new and traditional families distribute tasks along or across gender lines. For example, yard work, home maintenance, paper work (accounting), and grocery shopping which, according to the authors are the tasks which require the least skill and regularity, are traditionally male designated. On the other hand, laundry, cooking, housecleaning and dish washing, tasks which require more regularity and time, are female designated in traditional families. The authors find that childbearing tends to solidify traditional gender roles even in once egalitarian relationships. Conversely the young adults most prepared to cross gender lines and share domestic tasks more equitably appear to be those with a non-traditional family past, those who have experienced independent living, and young male adults with higher education. Overall, however, the authors warn that the current stress on children to be independent in new families has meant less and less sharing of household tasks on their part. The authors warn that this may leave whole generations unprepared for domestic work in either nonfamily or new family settings.

The book winds to a close by making general comments about domestic economy -- for example, that women's higher status in the family due to paid labour outside the home is leading to greater sharing of domestic labour, but more so with husbands than with children. The authors find this "reassuring" because "as more families come to accept the modern definition of a woman's place extending beyond the home, the prospects are improving for 'new families' rather than 'no families'"(191). In the last chapter, a hopeful note is sounded around the pressures to make men more egalitarian, the prime one being how desirable egalitarian attitudes make them on the mating market. The authors' strong bias for "new family" living finally emerges in explicit statements rather than subtext and are shown to rest largely on weakly supported hypotheses about the future: for example, that single people somehow automatically "forgo developing close, intimate, long-term relationships" by choosing to live alone and that because a system of single adults is "untested," it automatically follows that it is a risk for the future because "commitment and intimacy will be more difficult to achieve and maintain" (204). 
My chief discomfort with New Families, No Families? is brought to the fore by this conclusion. The authors' endorsement of one choice of family transformation over all others limits their study to prescriptive interpretations from the outset. This is a strange limitation at a time when American culture is featuring more and more images of alternative lifestyles: e.g. single-parent families, young single adults with successful support groups of friends, and homosexual couples; and at a time when questions about the definition of family are at the center of legal and legislative debates over spousal insurance, child-support and welfare payments, and tax deductions. Feminist readers and cultural studies readers of New Families, No Families? may be disappointed by the authors' refusal to engage with the more complex theoretical issues surrounding decisions that determine whose living arrangements and support network rate as family these days and why. I would have liked to see the authors situate their current ethical position more openly and in terms of a long tradition of maternal feminism, which may have helped to fill out their rather cursory history of the family as well. Given the book's tacit rejection of alternative lifestyles, however, it is difficult to trust that science alone can explain the complexities of current transformations of the family.

\section{Roxanne Rimstead}

